Toshiharu Kasaba MD, Gotaro Yoshikawa MD, Tomoko Seguchi MD, Mayumi Takasaki MD

\title{
Epidural fentanyl improves the onset and spread of epidural mepivacaine analgesia
}

Purpose: To determine the extent of enhanced blockade by the combined use of epidural fentanyl and mepivacaine. We compared the onset of hypoalgesia, analgesia and the threshold of pressure pain.

Methods: Thirty patients were randomly divided into three groups. The fentanyl group received $10 \mathrm{ml}$ saline containing $0.1 \mathrm{mg}$ fentanyl, mepivacaine group received $10 \mathrm{ml}$ mepivacaine $1 \%$ and a mixed group received $10 \mathrm{ml}$ mepivacaine $1 \%$ with $0.1 \mathrm{mg}$ fentanyl. All solutions, without epinephrine, were injected through an epidural catheter at $T_{5-6}$ to $T_{6-7}$. The change in sensation, loss of pin-prick and pain threshold sensation, measured by pressure algometer, were assessed at 2.5-min intervals for $15 \mathrm{~min}$ at the $T_{4}$ dermatome. Spread of analgesia was determined at $15 \mathrm{~min}$.

Results: Loss of pinprick was more rapid in the mixed, $11.0 \pm$ 2.7 (SD) min, than in the mepivacaine group, $15.0 \pm 2.9$ min, $(P<0.05)$, although there was no difference in change of sensation. Pressure pain threshold increased with time in the mepivacaine $(P<0.05)$ and mixed $(P<0.05)$ groups. It was higher in the mixed than in the fentanyl and mepivacaine groups at $5,7.5$ and $10 \mathrm{~min}(P<0.05)$. The lower level of analgesia was lower in the mixed than in the mepivacaine groups $(P<0.05)$. Blood pressure was unchanged in the three groups, but heart rate decreased at 7.5, 10, 12.5, and $15 \mathrm{~min}$ in the mepivacaine and mixed groups $(P<0.05)$.

Conclusions: The addition of fentanyl to mepivacaine accelerates the onset of analgesia and enhances the analgesic effect of epidural block.

\section{Key words}

ANAESTHETIC TECHNIQUE: epidural;

ANAESTHETICS, LOCAL: mepivacaine;

ANALGESICS: fentanyl;

From the Department of Anesthesiology, Miyazaki Medical

College, Kiyotake-Cho, Miyazaki, Japan.

Address correspondence to: Dr. T. Kasaba, Department of Anesthesiology, Miyazaki Medical College, Kiyotake-Cho, Miyazaki, 889-16, Japan.

Phone: 81-985-85-2970. Fax: 81-985-85-7179

Accepted for publication July 28, 1996.
Objectif: Déterminer l'importance de la facilitation du bloc épidural produite par la combinaison du fentanyl et de la mépivacaine. Ont été comparés le début de l'hypoalgésie, l'analgésie et le seuil de la douleur à la compression.

Méthodes: Trente patients étaient répartis aléatoirement entre trois groupes. Le groupe fentanyl recevait $10 \mathrm{ml}$ de sol.phys. contenant fentanyl $0,1 \mathrm{mg}$, le groupe mépivacaïne recevait mépivacaïne $1 \% 10 \mathrm{ml}$ et un groupe mixte recevait mépivacaine $1 \% 10 \mathrm{ml}$ avec fentanyl $0,1 \mathrm{mg}$. Toutes ces solutions non adrénalinées étaient injectées par un cathéter épidural situé entre $T_{5-6}$ et $T_{6-7}$. Le changement de sensation, la perte de sensation à la piqâre et le seuil douloureux, mesurés par un algomètre à pression étaient évaluées à des intervalles de 2-5 min pendant $15 \mathrm{~min}$ au dermatome $T_{4}$. Le niveau de l'analgésie était déterminé à la $15^{\mathrm{e}}$ min.

Résultats: La perte de la sensation à la piqûre survenait plus rapidement dans le groupe mixte, 11,0 2,7 (ET) min, que dans le groupe mépivacaüne, $15 \pm 2,9 \mathrm{~min}$, $(P<0,05)$, bien qu'aucune différence n'était notée sur le changement de sensation. Le seuil de la douleur à la compression augmentait avec le temps pour les groupes mépivacaïne $(P<0,05)$ et mixte $(P<0,05)$. Il était plus élevé dans le groupe mixte que dans le groupe fentanyl et mépivacaïne à $5,7,5$ et 10 min $(P<$ $0,05)$. Le niveau inférieur d'analgésie était plus bas dans le groupe mixte que les groupes mépivacaïne $(P<0,05)$. La pression artérielle était inchangée dans les trois groupes mais la fréquence cardiaque diminuait à $7,5,10,12,5$ et 15 min dans les groupes mépivacaïne et mixte $(P<0,05)$.

Conclusion: L'addition de fentanyl à la mépivacaïne accélère le début de l'analgésie et renforce l'effet analgésique du bloc épidural.

The use of epidural opioids for pain relief is well established. ${ }^{1,2}$ The combination of epidural bupivacaine and fentanyl is used widely for Caesarean section to improve the quality of perioperative analgesia. ${ }^{3-9}$ However, the onset time of analgesia in their reports was not affected by the addition of fentanyl to bupivacaine. The combination of other local anaesthetics such as mepivacaine, which is commonly used in our hospital, has not been clearly investigated. Boidin et al. ${ }^{10}$ 
reported that epidural fentanyl enhanced the quality of epidural blockade when combined with mepivacaine but the onset time of sensory analgesia was no different. Previously, Koganemaru et al. ${ }^{11}$ reported that the combined use of fentanyl and mepivacaine in the epidural space produced a rapid onset and wide spread of analgesia. To examine more clearly whether epidural fentanyl with mepivacaine enhanced the onset of analgesia, we compared not only analgesia but also hypoalgesia and threshold of pressure pain.

This study was designed to investigate the analgesic interaction of a mixture of fentanyl and mepivacaine, compared with the analgesia produced by fentanyl or mepivacaine alone. The purpose of this study was to determine whether the addition of fentanyl to mepivacaine accelerated the onset of hypoalgesia and analgesia as assessed by pin-prick or increased the threshold of pressure pain.

\section{Methods}

The study was approved by the human research review committee of our institute, and informed consent was obtained from each patient. Thirty patients, ASA I or II, undergoing lobectomy or mastectomy were studied. They were randomly divided into three groups: a fentanyl group received $10 \mathrm{ml}$ saline solution containing $0.1 \mathrm{mg}$ fentanyl; a mepivacaine group received $10 \mathrm{ml}$ mepivacaine $1 \%$; a mixture group received $10 \mathrm{ml}$ mepivacaine $1 \%$ with $0.1 \mathrm{mg}$ fentanyl. All solutions administered in the epidural space contained no epinephrine. Demographic details are shown in Table I.

All patients received were premedication with $0.5 \mathrm{mg}$ benzodiazepine po $1.5 \mathrm{hr}$ before induction of anaesthesia. With patients in the lateral decubitus position and after 2-3 ml lidocaine $1 \%$ for local anaesthesia, the epidural space was identified by loss of resistance to saline using a 17-gauge Tuohy needle at the $T_{5-6}$ or $T_{6-7}$ interspace. An epidural catheter was inserted $3 \mathrm{~cm}$ cephalad and the patient was turned supine. A test dose was not used. Each solution was injected epidurally over one minute.

The onset of cutaneous hypoalgesia and analgesia were observed at 2.5 -min intervals using pin-prick at the mid-thoracic region at the $\mathrm{T}_{4}$ dermatome. Fifteen minutes after the initial injection of opioid and/or local anaesthetic, the spread of analgesia was determined by pin-prick. Latency of onset was defined as the time between the extradural injection and the appearance of hypoalgesia or analgesia. Hypoalgesia was assessed subjectively by the patient as a decrease in pain to pin-prick, compared with pain produced by pin-prick at the shoulder as a reference. Analgesia was assessed as the loss of pain sensation by pin-prick. The threshold of pressure pain was determined at 2.5-min intervals using a spring pressure algometer (Attukei, Igarashi-ika -kogyo, Tokyo, Japan ) with a $50 \mathrm{~mm}^{2}$ circular probe on the sternum at the $T_{4}$ dermatome. The loading rate was set at $0.5 \mathrm{~kg} \cdot \mathrm{sec}^{-1}$ and the cut-off level at 6 $\mathrm{kg}$. Systolic and diastolic blood pressures were measured by oscillometer at 2.5 -min intervals, and heart rate was measured from the ECG. The haemodynamic data and haemoglobin oxygen saturation were displayed on a Nihon-koden BSM-8500 monitor (Nihonkoden, Tokyo, Japan) and recorded on a recorder (Nihon-koden, Tokyo, Japan). Side effects, such as respiratory depression, itching, nausea and vomiting were assessed. Oxygen was administered when haemoglobin oxygen saturation decreased $<93 \%$. The $\mathrm{pH}$ of each solution was determined with a $\mathrm{pH}$-meter (accumet model 15, Fisher Scientific, USA).

After the studies, anaesthesia was induced in all patients with thiopentone $\left(5 \mathrm{mg} \cdot \mathrm{kg}^{-1}\right)$ and maintained with epidural block and nitrous oxide, oxygen and a low concentration of sevoflurane Muscle relaxation was produced with vecuronium $\left(0.15 \mathrm{mg} \cdot \mathrm{kg}^{-1}\right)$ that facilitated tracheal intubation. The data were expressed as mean \pm SD or median (range) (the level of analgesia). Groups were analyzed using analysis of variance (ANOVA) or chi squared analysis. Anaesthetic characteristics between mepivacaine group and mixture group were analyzed using the Mann-Whitney $U$ test. Changes in the pressure pain were compared using the Kruskall-Wallis test. Changes in the haemodynamic values were compared using repeated-measures analysis of variance and post hoc Fisher's procedure for multiple comparisons. Analyses were performed using Stat View (Abacus, Berkeley, CA). $P<0.05$ was considered statistically significant.

\section{Results}

There were no differences in the distributions of sex, age, weight, height and baseline variables among the three groups (Table I). The $\mathrm{pH}$ of the solution used in the fentanyl group $(5.1 \pm 0.04)$ was lower than that in the mepivacaine $(6.34 \pm 0.05)$ or mixture group $(6.33 \pm$ $0.04)(P<0.05)$.

Anaesthetic characteristics after epidural injection of fentanyl, mepivacaine or the mixture are shown in Table II. No hypoalgesia and analgesia was induced in the fentanyl group. The onset of analgesia was more rapid in the mixture than in the mepivacaine group $(P<0.05)$. The lower levels of analgesia were different between the mepivacaine and mixture groups $(P<0.05)$.

The threshold of pressure pain $(1.2 \pm 0.4 \mathrm{~kg}$ in the fentanyl group, $1.6 \pm 0.8 \mathrm{~kg}$ in the mepivacaine group, $1.5 \pm 0.6 \mathrm{~kg}$ in the mixture group) increased at $10(3.1 \pm$ 
TABLE I Demographic details in three groups (mean \pm SD)

\begin{tabular}{lccc}
\hline & $\begin{array}{l}\text { Fentanyl } \\
(n=10)\end{array}$ & $\begin{array}{l}\text { Mepivacaine } \\
(n=10)\end{array}$ & $\begin{array}{l}\text { Mixture } \\
(n=10)\end{array}$ \\
\hline Sex - M:F & $6: 4$ & $6: 4$ & $8: 2$ \\
Age $-\mathrm{yr}$ & $59 \pm 17$ & $55 \pm 11$ & $64 \pm 13$ \\
Weight $-\mathrm{kg}$ & $53 \pm 9$ & $55 \pm 6$ & $58 \pm 7$ \\
Height $-\mathrm{cm}$ & $157 \pm 9$ & $157 \pm 6$ & $161 \pm 11$ \\
BP $-\mathrm{mmHg}$ & $132 / 69 \pm 21 / 12$ & $124 / 65 \pm 12 / 9$ & $134 / 74 \pm 21 / 12$ \\
$\mathrm{HR}-\mathrm{mmHg}$ & $78 \pm 12$ & $80 \pm 12$ & $81 \pm 9$ \\
\hline
\end{tabular}

No significant differences among groups.

TABLE Il Anaesthetic characteristics after fentanyl, mepivacaine or mixture

\begin{tabular}{llll}
\hline & $\begin{array}{l}\text { Fentanyl } \\
(n=10)\end{array}$ & $\begin{array}{l}\text { Mepivacaine } \\
(n=10)\end{array}$ & $\begin{array}{l}\text { Mixture } \\
(n=10)\end{array}$ \\
\hline Hypoalgesia - min & - & $8.8 \pm 4.0$ & $7.0 \pm 2.0$ \\
Analgesia - min & - & $15.0 \pm 2.9$ & $11.0 \pm 2.7^{*}$ \\
Upper level analgesia & - & $\mathrm{T}_{3}\left(\mathrm{~T}_{1}-\mathrm{T}_{4}\right)$ & $\mathrm{T}_{3}\left(\mathrm{~T}_{2}-\mathrm{T}_{3}\right)$ \\
Lower level analgesia & - & $\mathrm{T}_{10}\left(\mathrm{~T}_{7}-\mathrm{T}_{12}\right)$ & $\mathrm{T}_{12}\left(\mathrm{~T}_{10}-\mathrm{L}_{5}\right)^{*}$ \\
\hline
\end{tabular}

$V$ alues mean $\pm \mathrm{SD}$ or median (range).

$* P<0.05$ vs mepivacaine group.

$1.9 \mathrm{~kg}), 12.5(4.4 \pm 1.9 \mathrm{~kg})$ and $15(5.1 \pm 1.2 \mathrm{~kg}) \mathrm{min}$ in the mepivacaine group $(P<0.05)$ and at $5(3.1 \pm 0.8$ $\mathrm{kg}), 7.5(4.2 \pm 1.5 \mathrm{~kg}), 10(5.1 \pm 1.3 \mathrm{~kg}), 12.5(5.8 \pm 0.1$ $\mathrm{kg})$, and $15(6.0 \pm 0.0 \mathrm{~kg}) \mathrm{min}$ in the mixture group $(P<0.05)$, but remained unchanged in the fentanyl group (Figure 1). The threshold was higher in the mixture group than in the fentanyl and mepivacaine groups at 5,7.5, and $10 \mathrm{~min}(P<0.05)$. At 12.5 and $15 \mathrm{~min}$, the threshold was higher in the mepivacaine and mixture groups than in the fentanyl group $(P<0.05)$, but no difference was found between the mepivacaine and mixture groups.

No changes in systolic and diastolic blood pressures were observed in the three groups (Figure 2). The heart rate decreased at $7.5\left(70 \pm 12,74 \pm 12 \cdot \mathrm{min}^{-1}\right), 10(68 \pm$ $\left.12,73 \pm 12 \cdot \mathrm{min}^{-1}\right), 12.5\left(68 \pm 12,72 \pm 12 \cdot \mathrm{min}^{-1}\right)$, and $15\left(69 \pm 12,68 \pm 12 \cdot \mathrm{min}^{-1}\right) \mathrm{min}$ in the mepivacaine and mixture groups $(P<0.05)$, respectively, but remained unchanged in the fentanyl group. There was no difference in heart rate between the mepivacaine and mixture groups. Additional low flows of oxygen were administered in three patients in the mixture group during the study, because haemoglobin oxygen saturation decreased $<93 \%$. Itching was seen in one patient in the fentanyl group: other side effects, such as nausea and vomiting were not seen.

\section{Discussion}

This study demonstrated that the addition of $0.1 \mathrm{mg}$

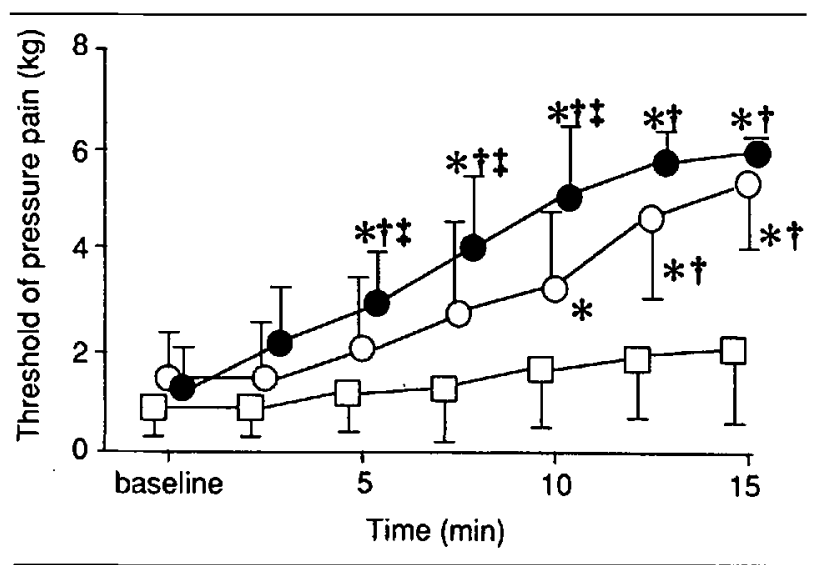

FIGURE 1 Changes in pressure threshold (mean \pm SD). Empty square $=$ fentanyl group, empty circle $=$ mepivacaine group, and filled circle $=$ mixture group. ${ }^{*} P<0.05$ vs baseline values; $\dagger P<0.05$ vs fentanyl group; $\ddagger P<0.05$ vs mepivacaine group.

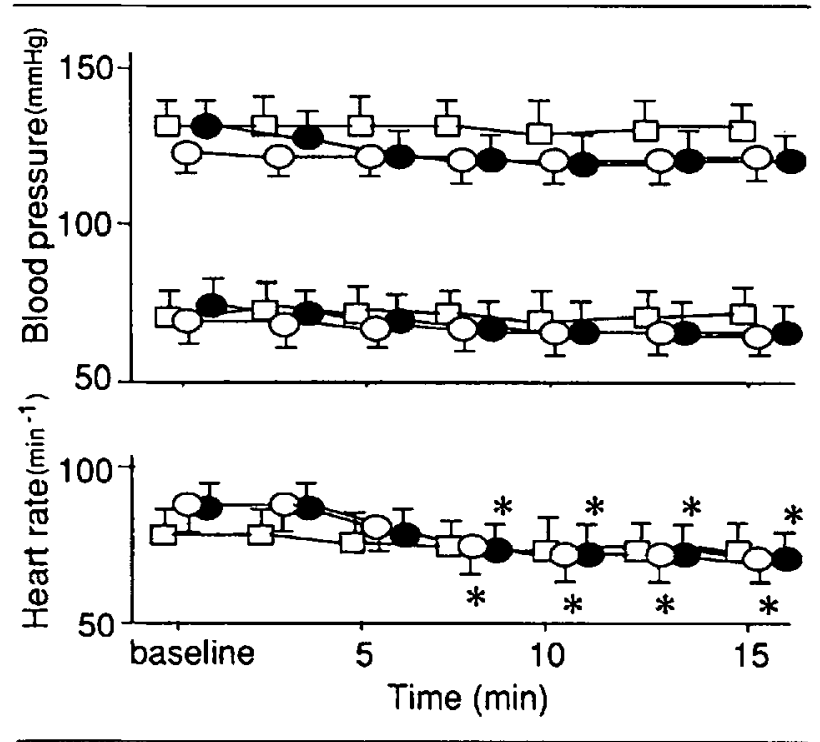

FIGURE 2 Haemodynamic changes (mean $\pm \mathrm{SD}$ ). (upper figure) changes of systolic and diastolic BP, (lower figure) change of HR. Empty square $=$ fentanyl group, empty circle = mepivacaine group, and filled circle $=$ mixture group. ${ }^{*} P<0.05$ vs baseline values.

fentanyl to mepivacaine $1 \%$ accelerated the onset of analgesia and increased the threshold of pressure pain during epidural analgesia without any haemodynamic changes.

Koganemaru et al." also demonstrated that fentanyl accelerated the onset of analgesia by about four minutes compared with mepivacaine alone. They used mepivacaine $2 \%$ with $0.1 \mathrm{mg}$ fentanyl and measured the onset time at one-minute intervals. However, Boidin et al. ${ }^{10}$ could not demonstrate the acceleration of the onset of analgesia by the addition of fentanyl. They used mepi- 
vacaine $2 \%$ with $0.05 \mathrm{mg}$ fentanyl and measured the onset time every five minutes. One reason for the difference may be the interval between measurements. Although we could not demonstrate acceleration of the onset of hypoalgesia, testing at one-minute intervals may have detected a difference. The dose ratio between mepivacaine and fentanyl may be another important reason for acceleration of the onset of analgesia. Boidin et al. ${ }^{10}$ used a ratio of $1 \mathrm{mg}: 0.25 \mu \mathrm{g}$, while Koganemaru et al. ${ }^{11}$ used a ratio of $1 \mathrm{mg}: 0.33 \mu \mathrm{g}$ for mepivacaine and fentanyl. Although the optimum dose ratio of local anaesthetics and opioids has not been determined, we used a ratio of $1 \mathrm{mg}: 1 \mu \mathrm{g}$. The dose ratio of epidural bupivacaine and fentanyl reported previously was $1 \mathrm{mg}$ : $4 \mu \mathrm{g}$ by Cooper and Turner ${ }^{12}$ and 1 mg: $5 \mu \mathrm{g}$ by George et al. ${ }^{13}$ Considering the potency ratio of bupivacaine and mepivacaine (4:1), the dose ratio of epidural mepivacaine and fentanyl in our study may be suitable.

In this study, pressure pain threshold increased rapidly in the mixture group although it remained unchanged in the fentanyl group. Many sensory components such as touch, pressure and pain are stimulated by a pressure algometer. Epidural opioids act on receptors in the spinal cord and block pain pathways selectively. ${ }^{14,15}$ Opioids inhibit neuronal activity in the dorsal horn evoked by $\mathrm{C}$ fibres more strongly than that evoked by $\mathrm{A} \delta$ fibres, whereas neuronal activity evoked by $\mathrm{A} \beta$ fibres is unaltered. ${ }^{16,17}$ Touch and pressure stimuli are conducted through $A \beta$ fibres which inhibit $A$ and $C$ fibres. ${ }^{18}$ Local anaesthetics easily block $A \delta$ and $C$ fibres, which conduct pain sensation, but at this time $A \beta$ fibres remain unblocked. The rapid onset of analgesia and increase of pressure pain threshold observed in this study is, therefore, likely the results from inhibitory effect of $A \beta$ fibres to $A \delta$ and $C$ fibres.

Alkalinization of local anaesthetic solutions has been shown to produce a more rapid onset and improved quality of sensory and motor blocks although clinical studies with alkalinized local anaesthetic solutions have produced controversial results. ${ }^{19}$ In this study addition of fentanyl to mepivacaine did not change the $\mathrm{pH}$ of the mepivacaine solution. Therefore, enhancement of analgesic efficacy is probably due to the analgesic effect of fentanyl.

We did not use test doses because the test dose itself blocks the sensory nerve at the $T_{4}$ dermatome which affects the onset of analgesia and pressure pain. In this study, no changes in systolic or diastolic blood pressures were observed in the three groups, although the heart rate decreased in the mepivacaine and mixture groups. The haemodynamic changes following epidural mepivacaine and fentanyl were similar to those following mepi- vacaine alone. Thus, the addition of fentanyl to local anaesthetics would not affect haemodynamics during epidural anaesthesia.

In conclusion, the addition of $0.1 \mathrm{mg}$ fentanyl to mepivacaine $1 \%$ accelerated the onset of analgesia and increased pressure pain threshold during epidural analgesia. Epidural injection of a mixture of local anaesthetic and fentanyl may be advantageous in clinical practice, when a rapid onset of epidural analgesia is required.

\section{References}

1 Cousins MJ, Mather LE. Intrathecal and epidural administration of opioids. Anesthesiology 1984; 61: 276-310.

2 Bromage PR, Camporesi E, Chestnut D. Epidural narcotics for postoperative analgesia. Anesth Analg 1980; 59: 473-80.

3 Rucci FS, Cardamone $M$, Migliori $P$. Fentanyl and bupivacaine mixtures for extradural blockade. $\mathrm{Br} J$ Anaesth 1985; 57: 275-84.

4 King MJ, Bowden MI, Cooper GM. Epidural fentanyl and $0.5 \%$ bupivacaine for elective Caesarean section. Anaesthesia $1990 ; 45: 285-8$.

5 Paech MJ, Westmore MD, Speirs HM. A double-blind comparisom of epidural bupivacaine and bupivacaine-fentanyl for Caesarean section. Anaesth Intensive Care 1990; 18: 22-30.

6 Noble DW, Morrison LM, Brockway MS, McClure JH. Adrenaline; fentanyl or adrenaline and fentanyl as adjuncts to bupivacaine for extradural anaesthesia in elective Caesarean section. Br J Anaesth 1991; 66: 645-50.

7 Gaffud MP, Bansal P, Lawton C, Velasquez N, Watson WA. Surgical analgesia for Caesarean delivery with epidural bupivacaine and fentanyl. Anesthesiology 1986; 65: 331-4.

8 Cohen SE, Tan S, Albright GA, Halpern J. Epidural fentanyl/bupivacaine mixtures for obstetric analgesia. Anesthesiology 1987; 67: 403-7.

9 Halonen PM, Paatero H, Hovorka J, Haasio J, Korttila K. Comparison of two fentanyl doses to improve epidural anaesthesia with $0.5 \%$ bupivacaine for Caesarean section. Acta Anaesthesiol Scand 1993; 37: 774-9.

10 Boidin MP, Sulimma H, Hamers SEES. Fentanyl in $2 \%$ mepivacaine compared with fentanyl in $0.5 \%$ bupivacaine: two parallel controlled double blind studies. Acta Anaesthesiol Belg 1991; 42: 93-9.

11 Koganemaru M, Suzuki N, Shimokawa A, Takasaki M. Epidural anesthesia induced with fentanyl and mepivacaine. (Japanese) J Clin Anesth 1994; 18: 1536-40.

12 Cooper DW, Turner G. Patient-controlled extradural analgesia to compare bupivacaine, fentanyl and bupivacaine with fentanyl in the treatment of postoperative pain. $\mathrm{Br} \mathrm{J}$ Anaesth 1993; 70: 503-7.

13 George KA, Chisakuta AM, Gamble JAS, Browne GA. 
Thoracic epidural infusion for postoperative pain relief following abdominal aortic surgery: bupivacaine, fentanyl or a mixture of both? Anaesthesia 1992; 47: 388-94.

14 Dickenson AH, Sullivan AF. Electrophysiological studies on the effects of intrathecal morphine on nociceptive neurons in the rat dorsal horn. Pain 1986; 24: 211-22.

15 Besse D, Lombard MC, Zajac JM, Roques BP, Besson JM. Pre- and postsynaptic distribution of $\mu, \delta$ and $k$ opioid receptors in the superficial layers of the cervical dorsal horn of the rat spinal cord. Brain Res 1990; 521: 15-22.

16 Doi $T$, Jurna I. Analgesic effect of intrathecal morphine demonstrated in ascending nociceptive activity in the rat spinal cord and ineffectiveness of caerulein and cholecystokinin octapeptide. Brain Res 1982; 234: 399-407.

17 Game CJA, Lodge D. The pharmacology of the inhibition of dorsal horn neurones by impulses in myelinated cutaneous afferents in the cat. Exp Brain Res 1975; 23: 75-84.

18 Melzack R, Wall PD. Pain mechanisms: a new theory. A gate control system modulates sensory input from the skin before it evokes pain perception and response. Science 1965; 150: 971-9.

19 Gaggero G, Meyer O, Van Gessel EV, Rifat $K$. Alkalinization of lidocaine $2 \%$ does not influence the quality. of epidural anaesthesia for elective Caesarean section. Can $\mathbf{J}$ Anaesth 1995; 42: 1080-4. 